\title{
Soft-linking bottom-up energy models with top-down input-output models to assess the environmental impact of future energy scenarios
}

\author{
Matteo V. Rocco ${ }^{1 *}$, Yassin Rady $^{2}$, Emanuela Colombo $^{1}$ \\ ${ }^{1}$ Department of Enery, Politecnico di Milano, via Lambruschini 4, Milano 20156, Italy \\ ${ }^{2}$ The America University in Cairo (AUC), AUC Avenue, New Cairo 11835, Egypt
}

Corresponding Author Email: matteovincenzo.rocco@polimi.it

https://doi.org/10.18280/mmc_c.790307

Received: 23 March 2018

Accepted: 28 May 2018

\section{Keywords:}

energy policy, energy modelling, developing countries, input-output analysis

\begin{abstract}
Traditional bottom-up energy models have been widely applied so far to assess the future energy technologies over a specific time horizon, quantifying the direct economic and environmental implications of future energy scenarios. However, such approaches ignore the interactions that the energy sector has with other sectors in the economy, hence failing in quantifying the global impact of future energy technologies.

This study assesses the economic and environmental impact of an institutional energy scenario in the Egyptian economy, by soft linking a bottom-up, technology-rich model (OSeMOSYS) with a top-down Input-Output model (IOA). Based on the prospective institutional scenarios for Egypt, the energy model assesses the evolution of the Egyptian electricity mix towards 2040 . Then, the future energy scenario has been applied to the IOA model in terms of change in energy technology mix, change in final demand of electricity and change in national GDP production.

It is found that while primary energy consumption and GHG emissions of the energy sector are likely to decrease in the next decades, a significant increase in the same indicators for all the other national sectors is expected, thus unveiling the need to increase and diversify the energy efficiency investments in all the Egyptian economy.
\end{abstract}

\section{INTRODUCTION}

Based on IEA forecasts, world energy demand will increase in the next decades, and the final consumption of electricity in 2040 will account for $40 \%$ of the world TFC. Developing countries (DCs) are considered to be the major driver for such increase, due to an expected $65 \%$ increase in urban population and a $135 \%$ increase in their per capita income with respect to the 2017 levels [1]. To ensure a sustainable growth of the world electricity sector, policy makers should define adequate power generation policies, ensuring deployment of sufficient capacity to meet the forecasted a demand increase, and complying with the guidelines of international agreements on climate change. In this perspective, a holistic overview about the consequences due to the evolution of the power sector, capable of including its direct, indirect and induced economic and environmental effects is essential.

So far, bottom-up energy optimization models have been applied to forecast the evolution of the power sector: such models define the least cost energy mix that allows to satisfy an exogenously defined energy demand [2], hence assessing the economic and environmental implications of future energy scenarios by looking at the energy sector only. To be suited for applications in DCs, the most important features of such models are the open source nature and the fast learning curves: among others, the Open Source Energy Modelling System (OSeMOSYS) has been recently adopted in DCs [3-5]. On the other hand, top-down optimization models are empirical models based on Leontief's Input-Output tables as data source [6]: such models provide a comprehensive overview of the national economy, while lacking in a detailed treatment of energy technologies. Therefore, they can be hardly adopted to investigate the prospected impact due to changes in the energy technology mix [7-8].

Due to the complementary features of the above-introduced approaches, benefits may arise from their integration, providing more comprehensive and informative insights related to future energy scenarios at the nationwide economy scale [9]. Even if joint applications of bottom-up and top-down models are common in developed economies (e.g. the TIMESMACRO model), such models are very complex and difficult to be implemented in contexts characterized by great uncertainty of input data such as DCs.

Among other DCs, Egypt will be one of main driver of the global increase in the energy demand $[1,10]$, with a forecasted annual growth rate of $6 \%$ in electricity use until 2035 . Egyptian power generation mix is currently composed by thermal power plants $(91.4 \%)$, hydro power plants $(7.3 \%)$, and renewables $(1.2 \%)$ [11]. Therefore, the reliability and security of electricity supply could be disrupted by eventual shortages in natural gas supplies, and the same effect may be caused by a shortage in water [12]. Since also many other sectors of the Egyptian economy strongly rely on primary fossils and water resources, and since both of them are strongly dependent by the economic productivity of the national economy, it is of paramount importance to assess the future demand for such resources by encompassing all the national economic sectors.

Although the Egyptian government has promoted various studies that exploit bottom-up modelling tools to manage the sustainable growth of the energy sector, the analysis of 
primary resources requirements by all the national economy in future energy scenarios has not been performed so far, and it is strongly invoked by the literature [13-14].

\subsection{Aim of the study}

The objective of this paper is twofold: first, a novel approach useful to soft-link bottom-up energy optimization models with linear top-down Input-Output macroeconomic model is proposed. Secondly, the proposed approach is applied to the Egyptian economy in order to assess the economic and environmental implications due to changes in electricity production mix occurring in future energy scenarios (20152040).

The proposed approach is suited for application in DCs because of the following features. First, it grounds on simple assumptions to assess the increase in economic productivity (i.e. change in national GDP) stimulated by the forecasted increase in electricity use. Secondly, it is based on a linear Input-Output model, which requires less input data to be characterized, without taking into account sophisticated market equilibrium mechanisms. Finally, it is based on opensource models and datasets, overweighting the complexity and richness of the state-of-the-art models.

The rest of the paper is structured as follows: after a short literature review provided in subsection 1.2, methods and models are presented in section 2 and the case study analysis and results are presented in section 3. Concluding remarks are collected in section 4 .

\subsection{Brief literature review}

Top-down and bottom-up optimization models are both classified based on the following categories:

(1) Comparative statics or dynamic analyses. The difference is that the former only considers two instants of time, disregarding the transition pathway. Calliope energy model [15] and standard Computable General Equilibrium models (CGE) [8] are examples of the former category, while the times model [16] and the dynamic CGE model belong to the latter category.

(2) Mechanisms complexity. A variety of mechanisms can be taken into account, such as market price equilibrium, stocks-flows dynamics, etc.

(3) Scope of the analysis. The models may cover one or multiple commodities or productive activities (electricity, heating, storage, etc.), and extended to one or multiple economies.

While bottom-up approaches are usually based on analytical models of the analyzed technologies, top-down models mostly rely on empirical datasets derived from Leontief's Input Output tables [6]. For this reason, application of simple and linear top-down models is usually referred as Input-Output analysis (IOA).

Even if the scope of top-down models is comprehensive, such models are characterized by high aggregation level: indeed, energy technologies are usually lumped together in one average "energy sector". For such reasons, the two approaches have complementary rather than opposite features, and this invite in developing methods for their joint use, usually called as "link". In this perspective, optimization models can be hard-linked or soft-linked. Hard-linked models consists in a mathematical merge of the two models into one single model: Jacobsen adopts this approach to assess the effectiveness of financial and technical instruments to reduce GHG emission in Denmark in a general equilibrium framework [17]. Likewise, Bauer et al. proposed the REMID$\mathrm{R}$ model, including energy, economy and climate models to assess the effect on public welfare due to the introduction of renewables in the energy mix [18]. Based again on market equilibrium mechanism and on a detailed technology characterization, the PRIMS model has been used in several studies to address the transformation of the European energy system and the effectiveness of several environmental policies [19]. Gargiulo and Gallachóir presented a detailed descriptions of other hard-linked models, such as MERGE and POLES, specifying their capabilities and limitations [20].

As an alternative to the hard-link approach, a soft-link usually consists in solving separately the top-down and bottom-up models, linking them through endogenous and exogenous variables in a closed loop that iteratively return one unique solution. In its most simplified form, soft-link can be established in two ways:

(1) Linking Top-down to Bottom-up. In this case, the focus is still on the energy sector only, and the top-down model works like and LCA model, assessing the indirect environmental consequences caused by the energy sector in future energy scenario.

(2) Linking Bottom-up to Top-down. In this case, results of the former are introduced as input for the latter: hence, the focus is now on the whole economy, assessing the economywide consequences due to future energy scenarios. The present work propose this second type of soft-link.

Messener et al. proposed a soft-link between MESSAGE and MACRO models, with the aim to assess the impact of energy supply costs on the national energy production mix in a general equilibrium framework [21]. Kober et al. linked a nonlinear macroeconomic model to an energy system model by considering the decreases in consumers' spending due to the introduction of carbon taxes [22]. Recently, Heinrich et al. assessed the impacts on the German economy of removing coal power plants through a soft-linked model: they revealed that the proposed phasing out is not sufficient for Germany to reach its target level on GHG emissions, and they highlight the relevant role of indirect GHG emissions caused by renewables and the related infrastructures [23].

\section{METHODS AND MODELS}

Based on the analyzed literature, the need to develop softlinked models to be suited for DCs applications has emerged, since the mathematical formulation inconsistencies between bottom-up and top-down models might hinder the integration between models in a hard-link architecture. In particular, developing soft-links between open-source energy optimization models (OSEMOSYS) and linear Input-Output models (IOA) emerged as the simplest and straightforward way to provide modeling frameworks for DCs.

This section presents a brief overview about the bottom-up and top-down models selected as the suited for assessing energy scenarios in DCs. Then, a soft-link procedure is introduced and detailed.

\subsection{Bottom-up energy system modeling}

In this study, the open-source OSeMOSYS energy model has applied to assess the evolution of the power sector. 
OSeMOSYS is a modular linear programming optimization model: it defines the least cost energy mix required to satisfy an exogenously defined electricity demand in a defined time horizon, that is, the energy production mix with the minimum overall levelized investment and O\&M costs [3].

The availability of resources, costs of technologies and sectoral electricity demand are exogenously provided to the model, which returns the following endogenous parameters: optimal primary energy consumption and $\mathrm{CO} 2$ emissions directly caused by the optimal energy mix, the total levelized investment and O\&M costs, the technology mix of installed capacity and energy generation. The constraints of the model assure that the production and investments of the new capacities of the various technologies will be confined to the exogenously defined maximum and minimum boundaries. Several other constraints can be introduced, related to resources availability, environmental taxes, and so on.

Further details of the model, including its mathematical formulation, solution algorithms, and other technicalities are out of the scope of the paper and can be retrieved in literature $[3,24]$.

\subsection{Top-down macroeconomic modeling}

Leontief's Input Output Analysis (IOA) has been selected as applied as the top-down modelling approach, relying on the open-source Full Eora 26 Multi-Regional Input Output Tables (Eora 26) [25]. The selection of this dataset is due to its features: it covers 187 countries (including DCs), each schematized through 26 segments, and including 35 different environmental extensions, covering air pollution, land occupation, resources extraction, and so on

The original format of Eora 26 hinders its integration to the results of bottom-up models because of the high aggregation level of the energy sector, which includes electricity, gas and water production, transmission and distribution activities. To be suited to be soft-linked with the bottom-up model, the IOA energy sector need to be disaggregated reaching the detail of the single power generation technologies.

The proposed disaggregation approach is mainly based on the method developed by Linder et al. [26], adopted to disaggregate the Chinse electricity generation sector. This method is defined as heuristic, since the lack of required data are complemented with Authors' own assumptions. In particular, the disaggregation of rows and columns of the input-output table is performed through the following phases:

(1) Disaggregation of the main commodities. This step consists in dividing the energy sector into "Electricity" and "Gas and Water" production, transmission and distribution activities, according to the ratio of the investments in the electricity sector to the total production of the original aggregated sector.

(2) Disaggregation of the electricity sector. This step distinguishes the "production" from the "transmission and distribution" activities, again according to the ratios of the investments in the transmission, distribution, and electricity generation to the total production of the whole electricity sector.

(3) Disaggregation of the power generation technologies. First, it is assumed that each national productive sector and households final demand consume electricity with the same technology mix, hence creating one new row of the inputoutput table for each technology. Secondly, columns related to each technology have disaggregated based on detailed techno- economic data of each technology.

Finally, in order to increase the functionality of the analysis and the ease of the soft-link, the resulting disaggregated table has converted into a hybrid units tables, by converting monetary transactions of electricity generation technology sectors in physical units (TWh). A consistency test should be performed after the disaggregation procedure in order to ensure the closure of the electricity generation balances.

Given one economy composed by $n$ sectors, each with s types of exogenous transactions (say, primary energy, GHG emissions, etc.), 1 electricity technologies, and considering a time frame of one year, the top-down model is represented by the operators defined by equation (1). In particular, $\mathbf{A}_{0}(n \times n)$ is the hybrid technical coefficients matrix, representing the links between all the national sectors. $\mathbf{f}_{0}(n \times 1)$ is the hybrid final demand vector, representing households expenditures. $\mathbf{b}_{0}(\mathrm{~s} \times \mathrm{n})$ is the hybrid exogenous transactions coefficients matrix, representing the direct resources consumptions or waste emissions of each sector per unit of product. Finally, matrices $\mathbf{C}_{U}(n-l \times l)$ and $C_{D}(l \times n-l)$ are respectively the Upstream and Downstream Cutoffs: for each energy technology, $\mathbf{C}_{\mathrm{U}}$ collects inventories of national products yearly required to support its production, while $\mathbf{C}_{\mathrm{D}}$ represents the amount of electricity delivered to all the other national sectors for each unit of their production.

$\mathbf{A}_{0}=\left[\begin{array}{ll}\mathbf{A}_{\mathrm{N}} & \mathbf{C}_{\mathrm{U}} \\ \mathbf{C}_{\mathrm{D}} & \mathbf{A}_{\mathrm{E}}\end{array}\right] ; \mathbf{f}_{0}=\left[\begin{array}{l}\mathbf{f}_{\mathrm{N}} \\ \mathbf{f}_{\mathrm{E}}\end{array}\right] ; \mathbf{b}_{0}=\left[\begin{array}{ll}\mathbf{b}_{\mathrm{N}} & \mathbf{b}_{\mathrm{E}}\end{array}\right]$

Once the hybrid system has characterized, the application of the Leontief production and impact models represented by equations (2) returns respectively the total production vector $\mathbf{x}_{0}(n \times 1)$ and the total exogenous transactions $\mathbf{R}_{0}(\mathrm{~s} \times \mathrm{n})$. The latter represents the consumption of resources and waste emissions directly caused by each economic sector in the baseline year.

$$
\mathbf{x}_{0}=\left(\mathbf{I}-\mathbf{A}_{0}\right)^{-1} \cdot \mathbf{f}_{0} \quad \rightarrow \quad \mathbf{R}_{0}=\mathbf{b}_{0} \cdot \hat{\mathbf{x}}_{0}
$$

\subsection{Soft-link procedure}

With reference to the literature review (paragraph 1.2), the proposed approach aims at linking OSEMOSYS model to an Input-Output model: therefore, the integrated model is useful to assess the economy-wide consequences due to the prospected changes in the national energy mix in future scenarios. The proposed soft-link is schematically represented in Figure 1. Optimal scenarios related to the evolution of the electricity generation sector is derived by the OSEMOSYS model: for each future year of the analysis, the detailed representation of sectoral electricity demand, the availability of resources and the operational and economical attributes of the power generation technologies are provided as exogenous parameters. The bottom-up model then returns the future shares of electricity production technologies, together with the associated economic costs, direct consumption of natural resources, pollutants and GHG emissions.

The future installed electricity production capacities and the related energy generation, endogenously computed by the bottom-up model, are then used to characterize the evolution of the energy sector in the top-down model. The soft-link is performed according to the "ceteris paribus" principle, that is, 
the only changes introduced in the IOA model are related to (1) the electricity generation mix, (2) the increased demand for electricity and (3) the related increase in GDP induced by the electrical energy availability. Therefore, it is assumed that production technology of all the other sectors will remain unchanged in future years, and equal to the baseline. The shock is implemented according to the following parallel steps:

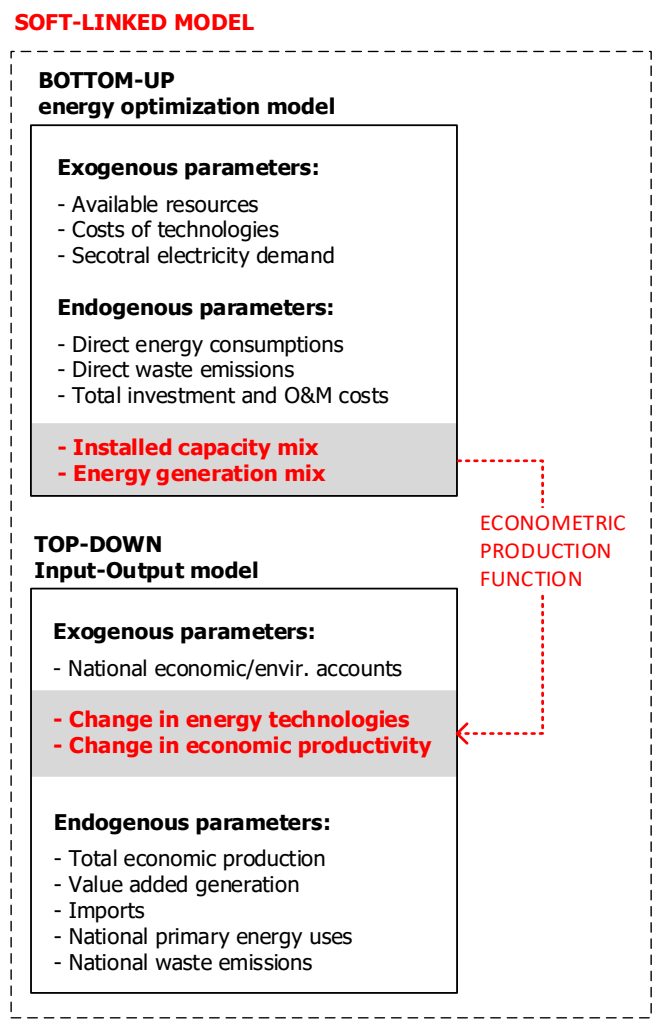

Figure 1. Schematic description of the defined soft-link

Step 1. Change in the power generation mix.

Technical coefficients related to the rows of the electricity generation technologies (the downstream cutoff $\mathbf{C}_{D} \rightarrow \tilde{\mathbf{C}}_{D}$ ) are changed to reflect the change in the energy mix: the sum of the latter coefficients for each economic sector is kept constant, while their relative shares change according to the prospected changes occurring in the electricity production mix.

Step 2. Change in electricity households' demand.

The future yearly amount of electricity produced by each technology and delivered to final users is fed to the IOA model by changing residential final demand of power generation technologies $\left(\mathbf{f}_{\mathrm{E}} \rightarrow \tilde{\mathbf{f}}_{\mathrm{E}}\right)$.

Step 3. Change in national economic productivity.

It is assumed that the increased demand for electricity by each national sector reflects the effect of an increased economic national productivity (Gross Domestic Product, GDP), and this is a reasonable assumption for DCs according to the literature [27]. Therefore, an econometric production function used to forecast the future increases in GDP resulting from an increased energy availability. Equation (3) represents the typical logarithmic shape of the production function, that links the national electricity production $\left(\mathrm{EE}_{\text {prod }}\right)$ with the GPD ( $\tilde{\mathbf{f}}_{\mathrm{N}}$ ), as function of the $\alpha$ and $\beta$ coefficients, statistically derived based on historical data. The whole GDP growth is then divided among the national final demands of each sector by considering fixed proportions among them equal to the baseline economy.

$$
\tilde{\mathbf{f}}_{\mathrm{N}}\left(G D P, E E_{\text {prod }}\right)=\alpha \cdot \ln \left(E E_{\text {prod }}\right)-\beta
$$

These shocks characterize the IOA model for the generic ith future year, as defined by (4).

$$
\mathbf{A}_{i}=\left[\begin{array}{cc}
\mathbf{A}_{\mathrm{N}} & \mathbf{C}_{\mathrm{U}} \\
\tilde{\mathbf{C}}_{\mathrm{D}} & \mathbf{A}_{\mathrm{E}}
\end{array}\right] ; \mathbf{f}_{i}=\left[\begin{array}{c}
\tilde{\mathbf{f}}_{\mathrm{N}} \\
\tilde{\mathbf{f}}_{\mathrm{E}}
\end{array}\right] ; \mathbf{b}_{0}=\left[\begin{array}{ll}
\mathbf{b}_{\mathrm{N}} & \mathbf{b}_{\mathrm{S}}
\end{array}\right]
$$

Finally, Leontief production and impact models are applied to the shocked economy in the ith year based on equation (5).

$$
\mathbf{x}_{i}=\left(\mathbf{I}-\mathbf{A}_{i}\right)^{-1} \cdot \mathbf{f}_{i} \quad \rightarrow \quad \mathbf{R}_{i}=\mathbf{b}_{0} \cdot \hat{\mathbf{x}}_{i}
$$

\section{APPLICATION TO EGYPT AND RESULTS}

This section presents and discusses the results obtained from applying the soft-link presented in the previous section to the case of Egypt between 2015 and 2040. The aim of the application is to assess:

(1) The economy-wide environmental implications due to the evolution of the electricity production sector, focusing on GHG emissions.

(2) The prospected mitigation potential of renewables installed capacities in future years, that is, the reduction in GHG emissions intensity expected per each GW installed capacity

\subsection{Background information: scenarios definition}

Two future scenarios of Egypt's power sector has modeled through OSeMOSYS: a Business As Usual scenario (BAU), and a scenario based on the formulation of prospected new energy policies and projections, by the Business Monitor International company (BMI).

For both the scenarios, the available non-renewable and renewable resources feed 12 different electricity generation technologies (including traditional thermoelectric plants, hydroelectric plants, wind and solar technologies), and a transmission grid distributes and delivers electricity to final users. Technical and economic data about the power technologies, has been collected from EEHC and from the available literature [11, 29].

For the period enclosed between 2015 and 2040, BAU and BMI scenarios define the demand of electricity, the amount of energy required by each sector in each time slice, and the physical, technical or political constraints for the development of energy technologies (i.e. resources availability, taxes on resources use, phase out of specific energy sources, and so on). Notice that to obtain a detailed temporal description electricity demand, each year of the planning horizon has been divided to 15 time-slices according to the hourly and monthly load profile provided by the Egyptian Electricity Holding Company (EEHC) [11].

The two scenarios assumes detailed forecasts related the increase in national electricity demand till 2024, while a constant growth rate of $3.8 \%$ is assumed after 2024; the shares of the sectoral electricity demand is assumed as constant and equal to the baseline year [28]. Both the scenarios have been constrained according to the official released data: in particular, the upper bound on the installed hydropower 
capacity of $2.8 \mathrm{GW}$, since Egypt has deployed the available hydropower resources. Similarly, the maximum investment in capacity of Combined Heat and Power plants is defined to be zero, as the Egyptian government has no published plans in this technology at the current time [11].

The BAU scenario projects the current policies without introducing any novel development strategy for the energy sector, while the BMI scenario includes the new and prospected policy decisions: as an instance, the upper bounds of natural gas production has been set according to the forecasts of BMI Oil and Gas Report [30].

\subsection{Input data: Results of the osemosys model}

For each one of the above-introduced scenarios, the OSeMOSYS model returns the least-cost electricity generation mix, the capacity expansions required to meet the forecasted growth in demand and the direct energy use and emissions of such technology mix. Figure 2 shows the electricity production for the two analyzed scenarios in the considered time horizon.

The energy generation mix obtained according to the BMI scenario significantly differs from the energy mix derived from the BAU scenario. In the BMI scenario, the share of the thermal power plants (natural-gas steam cycle, natural-gas open cycle and natural-gas combined cycle) is approximately constant over the period between 2015 and 2040, due to the imposed constraints on natural gas supplies defined according to the literature. Hence, significant investments to increase the capacities of wind and photovoltaic rooftop technologies are required to meet the forecasted increase in demand. As a result, the share of the renewables in the power generation mix is likely to increase from $8 \%$ in 2015 to approximately $70 \%$ in 2040. On the other hand, the share of the hydropower generation is likely to be constant, as Egypt has exploited the available hydro resources for power generation. These results will have major economic and environmental implications that are different from those of the BAU scenario, where the natural gas supplies needed by thermal power plants in 2040 would exceeds the levels of 2015 by three times.
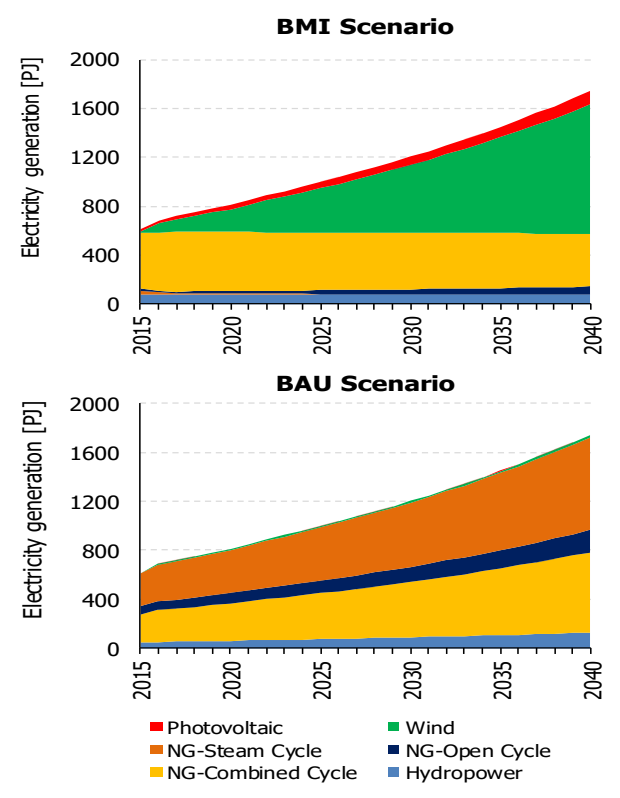

Figure 2. Electricity generation mix in the BMI and BAU scenarios between 2015 and 2040

\subsection{Application of the soft-link: results and discussion}

A variety of economic and environmental impacts can be derived from the soft-linked model, such as the value added generation, primary energy use, GHG emissions, pollutants emissions, water use, and so on. For the sake of simplicity, only GHG emissions are here considered. Figure 3 collects the direct $\mathrm{GHG}$ emissions related to the analyzed time window for the BAU and the BMI scenarios: notice that emissions are related to all the sectors of the economy, and not only to the energy sector, and they are aggregated per sector groups.

In the BMI scenario, penetration of renewables in the energy experiences a constant increase, reaching and exceeding the $70 \%$ of the whole energy mix in 2040 thanks to the strong investments in wind technology. For such reason, the GHG emissions of the energy sector decrease continuously, despite the increased electricity demand (see Figure 3, violet category). The opposite result holds for the BAU scenario, where renewable penetration are kept to the constant level of $10 \%$ of the whole mix, mainly constituted by hydropower technology. Since electricity demand is supplied by natural gas fueled thermoelectric plants, GHG emissions of the energy sector in this scenario are expected to grow continuously till 2040.

Considering the economy as a whole, both the analyzed scenarios are not able to limit the growth of GHG emissions. This reveals that, despite the strong investments in renewables prospected by the BMI scenario, which contributes in reducing the emissions of the power sector by about $40 \%$, economic efforts in the energy sector alone are not sufficient to reduce the overall national GHG emissions, which increases by about $18 \%$ in 2040 with respect to the baseline economy.
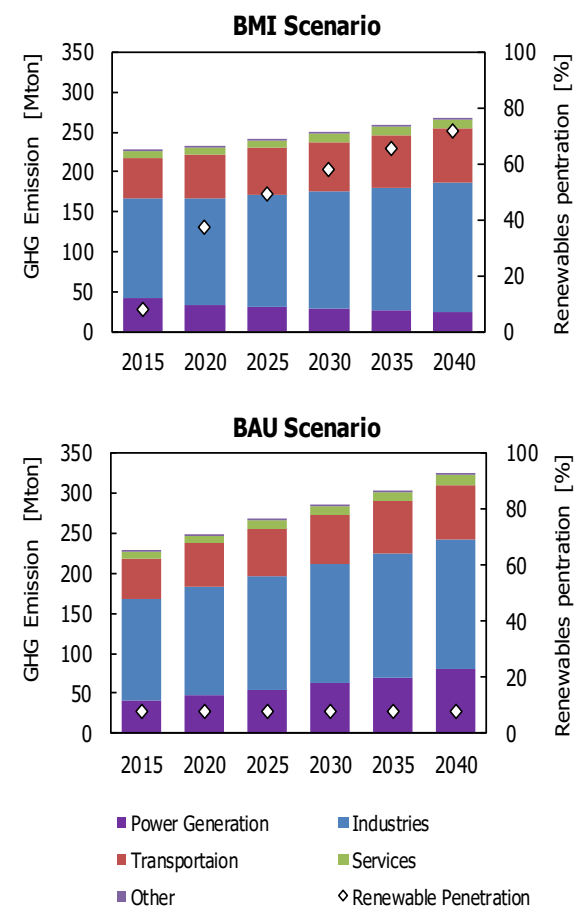

Figure 3. Direct sectoral GHG emissions in the BMI and BAU scenarios between 2015 and 2040, obtained from the soft-linked model

This result is mainly due to the fact that, based on national environmental accountings, the share of GHG emissions of the power generation sector of Egypt in 2015 has a limited 
contribution (18\%) with respect to the total GHG production. Moreover, the increased GHG emissions from the industrial, services, and transportation sectors induced by the increased in electricity availability overweigh the savings achieved by the power generation sector, leading to an increase from 227 Mton to 267 Mton between 2015 and 2040. Comparing BMI and BAU results, the $10.5 \%$ reduction in the total direct $\mathrm{CO}_{2}$ emission during the whole planning period could be increased by targeting the other $82 \%$ resembled by sectors other than power generation, and mainly focusing on the industrial sectors.

With reference to Figure 4, GDP is expected almost to double between 2015 and 2040. The economic efforts for decarbonization of the electricity sector in the BMI scenario seems to be effective between 2015 and 2020, where a decrease in $20 \%$ of the emissions intensity is expected. On the other hand, emissions intensity of the BAU scenario is expected to be about constant, since the GDP growth is supported by a constant share of electricity production mix.

\subsection{Real GHG emission intensity reduction of renewables}

From the obtained results, it can be inferred that investments in renewables seems not to have the same effectiveness in all the analyzed time window. Therefore, it may be useful to investigate and to quantify the effectiveness of the renewables installed capacity in displacing GHG emissions, hence supporting policymakers in defining informed energy policies and effective investments on renewables. Indeed, with reference to Figure 3, the question may arise whether it is reasonable to plan investments in renewables after 2030, instead of planning the same economic efforts in energy efficiency interventions in other sectors, industry among others.
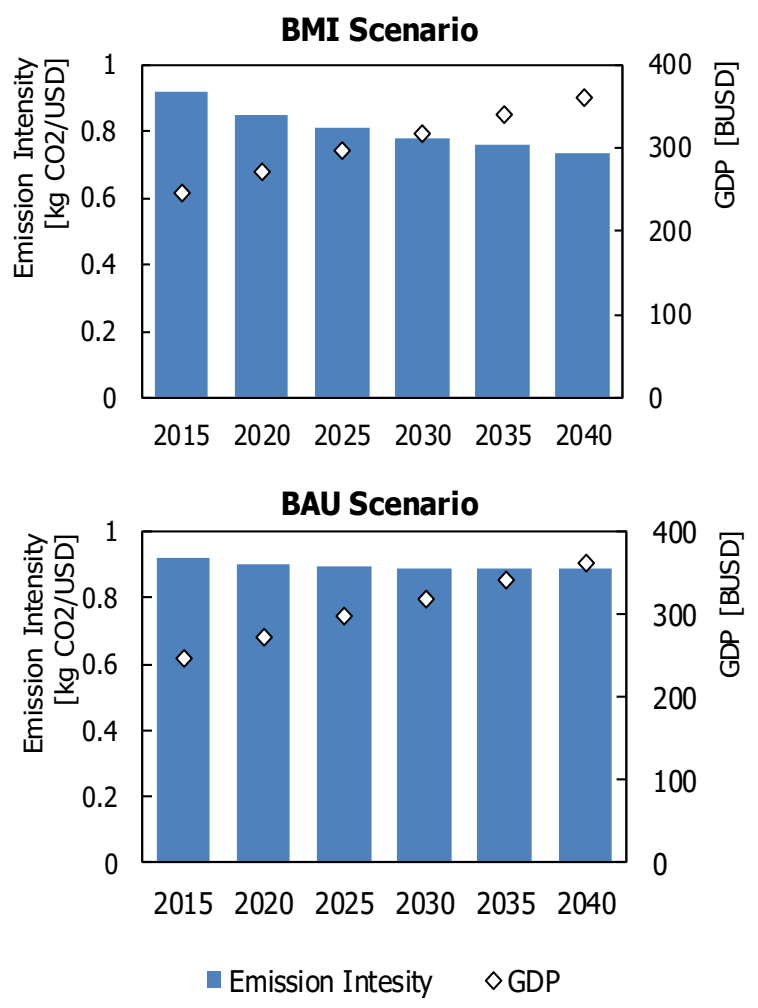

Figure 4. GHG emissions intensities and GDP in the BMI and BAU scenarios between 2015 and 2040, obtained from the soft-linked model
One indicator is here proposed to estimate the potential of the unit of renewables installed capacity in decreasing the GHG emissions intensity of the whole economy. Such indicator, simply defined renewable effectiveness $\varepsilon_{\text {ren }}$ and having dimensions of ( $\left.\operatorname{ton}_{\mathrm{CO} 2} / \mathrm{MUSD}\right) / \mathrm{GW}$, is evaluated according to equation (6) as the ratio between the change in the emissions intensity $\mathrm{e}_{\mathrm{GHG}}$ [ton/MUSD] between time $\mathrm{i}$ and time $i+1$ (here, the time slice is assumed as 5 years), and the change in renewables installed capacity $\mathrm{C}_{\text {ren }}[\mathrm{GW}]$ in the same time window.

$\varepsilon_{r e n, i \rightarrow i+1}=\left|\frac{e_{G H G, i+1}-e_{G H G, i}}{C_{r e n, i+1}-C_{r e n, i}}\right|$

Value of renewable effectiveness are collected in Figure 5: considering the energy intensity and the $\mathrm{CO}_{2}$ emissions intensity for the first five years of the planning horizon, investing in renewables would be 3-4 times more effective with respect to the period between 2035 and 2040. This could be explained by the expected significant reductions realized by the power generation sector during the first five years of the planning horizon, and by the consequences of the relevant increase in the expected national economic production.

Renewable effectiveness would fade out over the planning horizon due to the persistent increases in GHG emissions by the other sectors, driven by the GDP growth. The information introduced by such indicator may be useful for policymakers in order to support the definition of reasonable environmental targets and in defining the best way to reach such environmental goals.

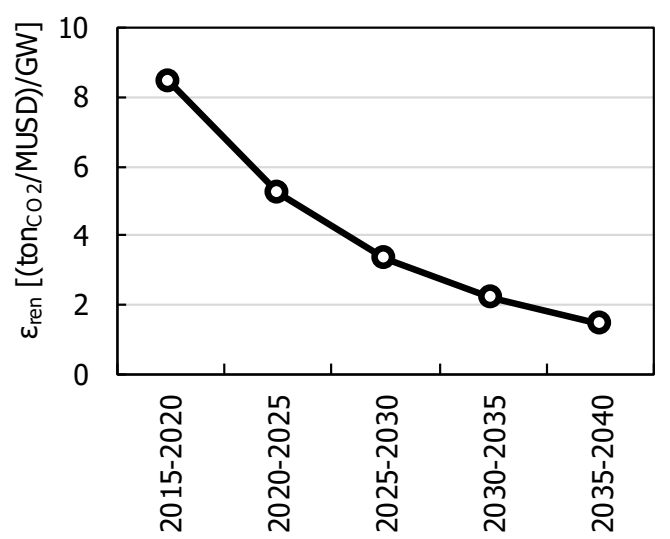

Figure 5. GHG emissions reduction potential of renewable installed capacity

\section{CONCLUSIONS}

This research shifts the frontiers the available literature of energy planning in developing countries by introducing a welldefined coupling methodology between two open-source bottom-up and top-down models based on the available data from authoritative institutions.

In particular, a soft-link between the open-source bottomup energy optimization model (OSEMOSYS) and a top-down linear Input-Output macroeconomic model (IOA) has been here proposed and formalized. Identifying the capabilities and the limitations of the two aforementioned models, the proposed soft-link is useful to identify the economic and 
environmental implications resulting from the evolution of the power sector on a nationwide economy scale. This return the economy-wide consequences due to future prospected changes in the electricity generation mix, such as the direct GHG emissions caused by all the sector of the economy. This approach can be extended to multiple indicators, and it is straightforward and based on simple one-way link between the two models.

The developed approach has been applied to the case of Egypt, where a significant increase in demand on electricity is forecasted. Considering the planning horizon between 2015 and 2040, the least cost power generation mix obtained through the OSeMOSYS model has been introduced as exogenous parameter in the IOA model.

Considering the $18 \%$ share in 2015 of the power sector in the production of country's GHG emissions, the reduction of GHG emissions of the electricity generation mix alone is not sufficient to reduce the prospected nationwide GHG emissions in 2040. Specifically, the expected increase in GHG emissions associated with the growth of Egypt's industrial, services, and transportation economic sectors exceeds the $40 \%$ reduction in the GHG emissions produced by the power sector.

Furthermore, assessing the effectiveness of increasing the installed capacities of renewable technologies has been quantitatively tackled in this study. It has been shown that the potential of the reductions GHG emissions fades out with time over the planning horizon, despite the continuous increase in renewables penetration. The major reductions in GHG emissions have been realized at the early years of the planning horizon: therefore, policy makers should consider the optimum time on which investments should be directed to increase the efficiency of industrial, services, and transportation sectors instead of keep investing in increasing renewables capacities, which will require associated investments in electricity transmission and distribution infrastructure.

\section{REFERENCES}

[1] Greening AL, Greene DL, Difiglio C, Agnew K Goldberg M, Attia S, et al. (2015). The outlook for energy: A view to 2040. Irving, Texas 2015. https://doi.org/10.1080/01998595.2012.10491656

[2] Pfenninger S, Hawkes A, Keirstead J. (2014). Energy systems modeling for twenty-first century energy challenges. Renew Sustain Energy Rev 33: 74-86. https://doi.org/10.1016/j.rser.2014.02.003

[3] Howells M, Rogner H, Strachan N, Heaps C. (2011). OSeMOSYS: the open source energy modeling system: an introduction to its ethos, structure and development. Energy Policy 2011.

[4] Taliotis C, Shivakumar A, Ramos E, Howells M, Mentis D, Sridharan V, et al. (2016). An indicative analysis of investment opportunities in the African electricity supply sector - Using TEMBA (The Electricity Model Base for Africa). https://doi.org/10.1016/j.esd.2015.12.001

[5] Nikolaus PDMG, Fernando LLL, Pe G, Balderrama N, Howells M. (2017). South America power integration, Bolivian electricity export potential and bargaining power: An OSeMOSYS SAMBA approach. Energy Strateg Rev 17: 27-36. https://doi.org/10.1016/j.esr.2017.06.002

[6] Miller RE, Blair PD. (2009). Input-output analysis:
Foundations and extensions. Cambridge University Press. [7] Miller RE, Blair PD. (1985). Input-output analysis.

[8] Hosoe N, Gasawa K, Hashimoto H. (2010). Textbook of Computable General Equilibrium Modelling: Programming and Simulations. New York St Martin's Press Palgrave Macmillan, Pp Xix 235 2010:2-NaN, 235. https://doi.org/10.1017/CBO9781107415324.004

[9] Böhringer C, Rutherford TF. (2008). Combining bottomup and top-down. Energy Econ 30: 574-96. https://doi.org/10.1016/j.eneco.2007.03.004

[10] World Bank Egypt, Arab Rep. (2017). Data, World Bank.

[11] Egyptian Electricity Holding Company. Annual Report 2014-2015. Cairo: 2015.

[12] Omar MEDM, Moussa AMA. (2016). Water management in Egypt for facing the future challenges. J Adv Res 7 : 403-12. https://doi.org/10.1016/J.JARE.2016.02.005

[13] Program TARES. (2016). The EU promotes Governance Energy Efficiency in cooperation with the Ministry of Energy and Renewable Energy and Ministry of Petroleum and Mineral Resources. Cairo: 2016.

[14] TARES S. (2014). Update on Energy Strategy Modelling TIMES-EGYPT. Cairo: 2014.

[15] Pfenninger S. (2017). Dealing with multiple decades of hourly wind and PV time series in energy models: A comparison of methods to reduce time resolution and the planning implications of inter-annual variability. Appl Energy 197: 1-13. https://doi.org/https://doi.org/10.1016/j.apenergy.2017.0 3.051

[16] Loulou R, Remme U, Kanudia A, Lehtila A, Goldstein G. Documentation for the TIMES Model - Part II. IEA Energy Technol Syst Anal Program 2016: 1-78.

[17] Klinge JH. (1998). Integrating the bottom-up and topdown approach to energy-economy modelling: the case of Denmark. Energy Econ 20: 443-61. https://doi.org/10.1016/S0140-9883(98)00002-4

[18] Bauer N, Baumstark L, Leimbach M. (2012). The REMIND-R model: the role of renewables in the lowcarbon transformation-first-best vs. second-best worlds. Clim Change 114: 145-68. https://doi.org/10.1007/s10584-011-0129-2

[19] (2014). E3MLab/ICCS at National Technical University of Athens. PRIMES - Detailed Model Description. Athens: 2014.

[20] Gargiulo M, Gallachóir BÓ. (2013). Long-term energy models: Principles, characteristics, focus, and limitations. Wiley Interdiscip Rev Energy Environ 2: 158-77. https://doi.org/10.1002/wene.62

[21] Messner S, Schrattenholzer L. (2000). MESSAGEMACRO: linking an energy supply model with a macroeconomic module and solving it iteratively. Energy 25: 267-82.

[22] Kober T, Summerton P, Pollitt H, Chewpreecha U, Ren X, Wills W, et al. (2016). Macroeconomic impacts of climate change mitigation in Latin America: A crossmodel comparison. Energy Econ 56: 625-36. https://doi.org/10.1016/J.ENECO.2016.02.002

[23] Heinrichs HU, Schumann D, Vögele S, Biß KH, Shamon H, Markewitz P, et al. (2017). Integrated assessment of a phase-out of coal-fired power plants in Germany. Energy 126: https://doi.org/10.1016/J.ENERGY.2017.03.017
285-305. 
[24] Moksnes N, Welsch M, Gardumi F, Shivakumar A, Broad O, Howells M, et al. (2015). Working Paper Series 2015 OSeMOSYS User Manua.

[25] Lenzen M, Kanemoto K, Moran D, Geschke A. (2012). Mapping the Structure of the World Economy. Environ Sci Technol 46: 8374-81. doi:10.1021/es300171x.

[26] Lindner S, Legault J, Guan D. (2013). Disaggregating the electricity sector of china's input-output table for improved environmental life-cycle assessment. Econ Syst Res 25: 300-20. https://doi.org/10.1080/09535314.2012.746646

[27] Ozturk I. (2010). A literature survey on energy-growth nexus. Energy Policy 38: 340-9. https://doi.org/10.1016/j.enpol.2009.09.024

[28] BMI Research (A Fitch Group Company). Egypt Power Report Q2 2016. London: 2016.

[29] Davidsson S, Hagberg AK, Estimatin S, Davidsson AK, Hagberg, (2017). Estimating investment needs for the power sector in the african region, kth, 2014. https://www.diva portal.org/smash/get/diva2:770120/FULLTEXT01.pdf (accessed June 11, 2017).g investment needs for the power sector. Kth, 2014.

[30] BNI Research. (2016). Report gas. oil \& gas report Egypt oil \& gas report Q4 2016. London: 2016.

NOMENCLATURE

\begin{tabular}{|c|c|}
\hline Symbol & Name, Unit \\
\hline $\mathrm{A}$ & Technical coefficients matrix, MUSD \\
\hline $\mathrm{f}$ & Final demand vector, MUSD \\
\hline $\mathrm{b}$ & $\begin{array}{l}\text { Exogenous transactions coefficients matrix, } \\
\text { ton }_{\mathrm{CO} 2} / \mathrm{MUSD}\end{array}$ \\
\hline $\mathrm{C}_{\mathrm{D}}$ & Downstream Cutoff matrix, TWh/MUSD \\
\hline $\mathrm{R}$ & Exogenous transactions matrix, ton $\mathrm{CO}_{\mathrm{CO}}$ \\
\hline $\mathrm{x}$ & Total production vector, MUSD \\
\hline I & Identity matrix, - \\
\hline GDP & Gross Domestic Product, MUSD \\
\hline $\mathrm{EE}_{\text {prod }}$ & Electrical energy production, TWh \\
\hline$\alpha, \beta$ & $\begin{array}{l}\text { Econometric production function } \\
\text { coefficients }\end{array}$ \\
\hline
\end{tabular}

Subscripts

0

$\mathrm{N}$

E

i
Number of sectors in the country

Baseline year

National economy

Energy sector

i-th year 